\title{
MODEL PERANGKAT PEMBELAJARAN KETERAMPILAN BERBICARA DENGAN PENDEKATAN KOMUNIKATIF KONTEKSTUAL BAGI MAHASISWA ASING
}

\author{
Mohamad Jazeri \\ IAIN Tulungagung \\ email: abahfuad69@yahoo.com
}

\begin{abstract}
Abstrak
Penelitian ini bertujuan mengembangkan perangkat pembelajaran berbicara bahasa Indonesia dengan pendekatan komunikatif-kontekstual bagi mahasiswa asing di IAIN Tulungagung. Desain pengembangan mengunakan model R2D2 (Recursive Reflective Design and Development) dari Willis. Produk yang telah dikembangkandiujicobakan kepada 20 mahasiswa BIPA dari Thailand, 2 instruktur BIPA, dan 1 ahli pembelajaran BIPA. Uji efektivitas dengan rancangan pra-eksperimen, yakni dengan melakukan tes awal dan tes akhir pada kelompok tunggal tanpa kelompok kontrol. Hasil penelitian menunjukkan bahwa $87 \%$ pebelajar merasa antusias dan senang karena contoh ungkapan dan dialog yang disajikan dalam buku ajar membantu mereka mampu berbicara bahasa Indonesia dengan lancar. Hasil uji-t menunjukkan perbedaan yang signifikan antara skor tes awal dan tes akhir. Dengan demikian dapat disimpulkan bahwa perangkat pembelajaran yang dikembangkan berpengaruh secara signifikan terhadap hasil pembelajaran keterampilan berbicara pada mahasiswa asing di IAIN Tulungagung.
\end{abstract}

Kata kunci: keterampilan berbicara, pendekatan komunikatif-kontekstual, Bahasa Indonesia untuk Penutur Asing (BIPA)

\section{A MODEL OF A LEARNING PACKAGE FOR THE SPEAKING SKILL USING THE CONTEXTUAL COMMUNICATIVE APPROACH FOR FOREIGN STUDENTS}

\begin{abstract}
This study aims to develop a learning package for the Indonesian language speaking skill using the contextual communicative approach for foreign students at IAIN Tulungagung. The developmentdesign used the R2D2 (Recursive Reflective Design and Development) model adopted from Willis's model (1995). The developed product was tried out to 20 BIPA (Bahasa Indonesia untuk Penutur Asing = Indonesian Language for Foreign Speakers) students from Thailand, 2 BIPA instructors, and 1 BIPA teaching expert. The effectiveness testing employed a pre-experimental design by administering a pretest and a posttest to a single group without a control group. The result of the study showed that $87 \%$ of the students felt enthusiastic and happy because the examples of expressions and dialogs provided in the textbook helped them to speak the Indonesian language fluently. The result of the t-test analysis showed a significant difference between the pretest scores and the posttest scores. Therefore, it is concluded that the developed learning package significantly affects the speaking skill of the foreign students at IAIN Tulungagung.
\end{abstract}

Keywords: speaking skill, contextual communicative approach, BIPA 


\section{PENDAHULUAN}

Indonesia adalah negeri yang besar dan kaya dilihat dari aspek geografis, demografis, ekonomi, politik, sosial, budaya, dan agama. Karena itu, Indonesia memiliki posisi strategis dalam percaturan dunia. Posisi tersebut membuat Bahasa Indonesia dipelajari di berbagai negara, baik di Asia, Eropa, Amerika, maupun Australia.

Secara geografis, Indonesia terletak di antara dua benua dan dua samudera. Karenanya, Indonesia memiliki objek wisata indah yang menggiurkan wisman asing.Jumlah penduduk yang besar, sebagai negara urutan keempat berpenduduk terbesar dunia, membuat Bahasa Indonesia memiliki jumlah penutur yang cukup signifikan. Tentu dengan jumlah penduduk yang banyak tersebut, Indonesia menjadi negara yang menguntungkan untuk berinvestasi demi keuntungan ekonomi.

Secara politis, Indonesia menganut politik luar negeri yang bebas-aktif yang membuat Indonesia sebagai negara tujuan yang aman. Selain itu, Indonesia dihuni oleh beragam etnis yang masing-masing memiliki budaya yang berbeda sehingga membuat Indonesia sebagai negara kaya budaya.

Selain kekayaan sumber daya manusia, sumber daya alam, dan budaya, Indonesia juga kaya akan agama dan kepercayaan. Tercatat ada lima agama resmi yang diakui negara di samping ratusan bahkan ribuan aliran kepercayaan yang tetap dilestarikan oleh para pengikutnya. Diantara agama tersebut, Islam memiliki pengkut terbanyak di Indonesia. Yang menarik adalah meskipun memiliki agama dan keyakinan yang berbeda, masyarakat Indonesia dapat hidup berdampingan, saling menghormati, dan saling menghargai tanpa gejolak yang memecah belah bangsa ini. Hal inilah diantara yang menyebabkan Islam Indonesia menjadi model pemikiran dan praktik keagamaan yang rahmatan lil 'alamin. Tidaklah mengherankan jika banyak negara Islam yang mengirimkan mahasiswanya untuk belajar Islam di Indonesia. Beberapa tahun ke depan akan semakin banyak mahasiswa asing yang belajar studi Islam di PTAI di Indonesia. Beberapa hal di atas, menurut Sammeng (1995) menjadi alasan mengapa semakin banyak orang asing mempelajari Bahasa Indonesia.

Pada awalnya, pengajaran Bahasa Indonesia untuk Penutur Asing (selanjutnya disebut BIPA) ini hanya sebagai bentuk pelayanan pengajaran bahasa Indonesia bagi beberapa mahasiswa yang berasal dari luar negeri. Namun, seiring posisi strategis di atas, kini permintaan pengajaran BIPA semakin meningkat. Di beberapa negara, seperti Perancis, Selandia Baru, Australia, dan Jepang Bahasa Indonesia menjadi salah satu mata pelajaran bahasa asing yang dipelajari di sekolah. Di Australia, Bahasa Indonesia diajarkan mulai sekolah dasar sampai perguruan tinggi. Buku ajar yang mereka gunakan secara luas adalah 'Bahasa Tetanggaku'. Bahkan di beberapa negeri jiran, seperti Malaysia dan Thailand, Bahasa Indonesia menjadi salah satu jurusan Regional Studies yang berangsur-angsur meningkat peminatnya.

Kini, pembelajaran BIPA tidak hanya diadakan di dalam negeri, melainkan juga di luar negeri. Menurut data Kementerian Pendidikan Tinggi tahun 2013, BIPA diajarkan di 45 negara yang tersebar di lima benua. Tidaklah mengherankan jika pada masa Masyarakat Ekonomi Asean (MEA) nanti bahasa Indonesia akan menjadi bahasa resmi ASEAN. Mengenai peluang ini, Susanto dan Rofiuddin (2015) berargumen bahwabahasa Indonesia adalah bahasa yang digunakan oleh mayoritas penduduk di ASEAN. Penduduk ASEAN berjumlah sekitar 600 juta jiwa dan sekitar 250 jutanya adalah penduduk Indonesia. Jadi ada sekitar sepertiga lebih penduduk ASEAN yang menggunakan bahasa Indo- 
nesia. Selain itu, bahasa Indonesia selain dipahami oleh orang Indonesia juga dipahami oleh sebagian besar etnis Melayu di Singapura, Malaysia, Brunai Darussalam, Filipina Selatan, Thailand Selatan, dan Timor Leste.

Argumen di atas, menurut Susanto dan Rofiuddin (2015) juga diperkuat dengan beberapa fakta, yaitu (1) bahasa Indonesia digunakan oleh mayoritas penduduk ASEAN (70 persen), (2) bahasa Indonesia menempati urutan ke-8 bahasabahasa yang digunakan oleh penduduk dunia, dan (3) bahasa Indonesia menempati urutan kedua bahasa yang mudah dipelajari oleh orang asing berdasakan hasil penelitian American Councils on the Teaching of Foreign Language tahun 2013. Maka dari itu, sangat logis jika bahasa Indonesia diusulkan menjadi bahasa ASEAN.

Hal senada disampaikan oleh Subangun (2014). Menurutnya, bahasa Indonesia berpeluang menjadi bahasa ASEAN karena lima alasan, yakni (1) kesederhanaan struktur, (2) jumlah penutur, (3) luas penyebaran, (4) minat orang asing mempelajarinya, dan (5) kekuatan diplomasi Indonesia di kawasan ASEAN. Bahasa Indonesia memiliki struktur yang sederhana, yakni tidak mengenal perubahan bentuk kata karena perubahan subjek dan waktu, tidak mengenal tingkatan bahasa seperti kasar-halus, dan tidak mengenal bacaan panjang-pendek yang mempengaruhi makna. Penutur bahasa Indonesia dan yang mampu memahami bahasa Indonesia tersebar di seluruh negara ASEAN. Bahasa Indonesia sudah tersebar di 45 negara di dunia dengan 219 lembaga penyelenggara pembelajaran bahasa Indonesia ini menunjukkan bahwa semakin banyak orang asing yang mempelajari bahasa Indonesia. Selain itu, di kawasan ASEAN, Indonesia memiliki diplomasi yang kuat.

Tentang hal ini seorang linguis James T. Collins (2014) menulis bahasa Melayu sebagai bahasa Dunia. Menurutnya, bahasa Melayu digunakan oleh etnis Melayu di beberapa negara ASEAN. Ia memberikan gambaran singkat perkembangan Bahasa Melayu dari tempat asalnya pada masa prasejarah di Kalimantan Barat hingga menyebar dengan cepat ke Sumatra, Semenanjung Malaya, Jawa bagian utara, Kalimantan bagian utara dan timur, Filipina barat serta Indonesia bagian timur. Ia menemukan dokumen bahasa Melayu yang berkaitan dengan budaya India, Persia, dan Arab serta berhubungan dengan unsur Cina, Jawa, dan Khmer. Unsur-unsur ini telah menghasilkan sebuah kekuatan dan kegunaan bahasa. Bahasa Melayu dalam hal ini juga termasuk bahasa Indonesia karena sejatinya bahasa Indonesia adalah bahasa Melayu yang disepakati bangsa Indonesia sebagai bahasa persatuan.

Beberapa Perguruan Tinggi Agama Islam (PTAI) sudah menerima mahasiswa asing yang belajar Islam di Indonesia (beberapa di antaranya adalah UIN Jakarta, UIN Malang, UIN Jogjakarta, UIN Riau, UIN Surabaya, dan UIN Bandung. Selain kampus-kampus besar tersebut baru-baru ini datang adalah mahasiswa Thailand di PTAI lain seperti STAIN Jember, STAIN Kediri, IAIN Tulungagung, dan STAINU Jakarta). Meskipun banyak sudah mahasiswa asing yang belajar di PTAI di Indonesia, PTAI tersebut secara khusus belum merancang pembelajaran BIPA sebagai jembatan untuk memahami materi kuliah yang diberikan di kelas. Hal ini berbeda dengan jika mahasiswa Indonesia kuliah di luar negeri. Mahasiswa yang kuliah di luar negeri mendapatkan pembelajaran bahasa Inggris yang disebut bridging program selama satu atau dua semester agar mampu mengikuti perkuliahan dengan baik. Di Indonesia, khususnya di PTAI layanan seperti itu masih dilakukan secara spontan dan terkesan asal-asalan. Untuk itu, penelitian ini ditujukan untuk menghasilkan bahan ajar BIPA, khusus- 
nya keterampilan berbicara, yang dapat digunakan sebagai bridging program sebelum mahasiswa mengikuti perkuliahan di kelas.

Dalam rangka menerima mahasiswa asing di IAIN Tulungagung, peneliti merasa perlu menyiapkan perangkat pembelajaran keterampilan berbicara dengan pendekatan komunikatif-kontekstual agar mahasiswa asing tersebut dapat menguasai Bahasa Indonesia dengan cepat, khususnya dalam berbicara. Dengan demikian mereka segera dapat mengikuti perkuliahan, yang rata-rata disampaikan dalam Bahasa Indonesia, dengan baik.

Pendekatan komunikatif memiliki lima prinsip yang perlu diperhatikan, yakni (1) interaksi komunikatif, (2) teks otentik, (3) belajar bahasa dan manajemen belajar, (4) pengalaman personal, dan (5) hubungan bahasa di kelas dan luar kelas (Nunan, 1991). Sementara pembelajaran kontekstual menekankan pada peristiwa dan situasi komunikasi. Pembelajaran ini menganggap keterampilan berbahasa sebagai satu kesatuan yang harus diajarkan dan dikembangkan sesuai dengan konteks penggunaanya, yakni peristiwa komunikasi yang otentik. Jadi, pendekatan komunikatif-kontekstual memandang pembelajaran keterampilan berbicara bahasa Indonesia harus berdasarkan kondisi nyata penggunaan bahasa.

Dalam hal pembelajaran berbicara, Ghazali (2010) mengemukakan bahwa tujuan pembelajaran di kelas adalah untuk menguasai dua kompetensi, yakni (1) mampu memahami tuturan mitra tutur, dan (2) mampu memproduksi tuturan yang mudah dipahami oleh mitra tutur. Di sini guru/dosen berperan untuk menciptakan kondisi agar kedua tujuan belajar bahasa tersebut tercapai. Untuk itu, ia menyarankan agar guru/dosen memiliki kompetensi untuk menentukan kebutuhan belajar siswa, tujuan pembelajaran, menyeleksi dan mengorganisasikan materi pembelajaran, mengelompokkan siswa sesuai kemampuan awal mereka, menyusun tugas-tugas yang bervariasi, serta membuat alat evaluasi dan penilaian.

Dalam kelas dengan pendekatan komunikatif, biasanya aktivitas-aktivitas kelas diorganisir sedemikian rupa untuk meningkatkan berbagai penggunaan bahasa secara fungsional dalam situasi sosial yang nyata. Situasi sosial tersebut antara lain salam, perkenalan, permintaan, perintah, pemberian informasi, dan ungkapan perasaan pribadi. Komunikasi yang otentik menuntut analisis terhadap berbagai materi dan tugas-tugas belajar agar tujuan pembelajaran dapat tercapai.

Pembelajaran BIPA termasuk dalam pembelajaran bahasa kedua. Tentang pembelajaran bahasa kedua, ada empat model teori yang berkembang selama ini, yakni (1) model pengondisian-operan, (2) model nativis LAD (Language Acquisition Devices), (3) model monitor, dan (4) model konstruksi kreatif (Saryono, 1992). Model pengondisian-operan diilhami oleh epistemologi Hume dan Locke dan logika Aristoteles atau logika induktif. Karenanya, model ini mengutamakan pengalaman inderawi, perilaku nyata, dan kemekanisan. Dengan demikian, res extensa dan aposteriori merupakan unsur primer sekaligus substansi dalam model ini, sedangkan res cogitan dan apriori hanyalah unsur sekunder. Di sini pebelajar dipandang sebagai individu yang pasif dan reaktif. Untuk itu, pebelajar dikendalikan oleh unsur lain yang lebih penting, yaitu lingkungan atau unsur luar pebelajar. Model ini menganggap bahwa keberhasilan belajar bahasa ditentukan oleh perlakuan-perlakuan yang diterima oleh pebelajar.

Model nativis LAD didasarkan pada epistemologi Descartes dan logika deduktif. Karenanya, model ini mementingkan rasionalisme, mentalisme, dan kreativisme. Dengan kata lain, model ini mengutamakan ego-intelegensi, kekodratian, dan 
daya cipta. Di sini pebelajar dipandang sebagai individu yang aktif dan kreatif yang dikendalikan oleh unsur yang terdapat dalam dirinya sendiri, yaitu struktur kejiwaan pebelajar. Model ini menganggap bahwa keberhasilan belajar bahasa ditentukan oleh struktur yang ada dalam dirinya sendiri, sedang lingkungan hanya menyediakan masukan (Chomsky dalam Saryono, 1992).

Kedua model belajar bahasa di atas masih menganut pandangan dualisme, yakni memandang salah satu unsur lebih dominan dibanding unsur lain (Saryono, 1992). Muncullah kemudian model monitor. Model ini dikemukakan pertama kali oleh Krashen (1981) dalam bukunya Second Language Acquisition and Second Language Learning. Disusul kemudian Principles and Praactice in Second Language Acquisition (1982). Model ini dilandasi oleh filsafat rasionalis dan paradigma linguistik generatif yang dikuatkan oleh temuan-temuan pembelajaran bahasa model nativis LAD. Rasionalisme digunakan adalah rasionalisme kritis Immanuel Kant. Rasionalisme Kant mencoba menjembatani antara rasionalisme Descartes dan empirisme Locke. Model ini juga bertumpu pada epistemologi Popper dengan logika deduktif-induktif. Sifat nativis dan rasionalisme kritis model monitor tampak pada konstruk dan paradigma teorinya yang tertuang dalam empat hipotesis. Empat hipotesis tersebut adalah (1) hipotesis pemerolehan dan belajar, (2) hipotesis urutan alamiah, (3) hipotesis monitor, dan (4) hipotesis penyaring afektif. Model ini lebih dikhususkan pada pebelajar dewasa.

Model konstruksi kreatif menganggap pebelajar sebagai individu yang bertindak aktif dan kreatif dalam belajar bahasa. Proses belajar dipandang sebagai interaksi antara unsur lingkungan bahasa dan proses internal dalam struktur kejiwaan pebelajar (Huda, 1984: 8). Belajar bahasa dipengaruhi oleh beberapa variabel indi- vidual pebelajar seperti lingkungan bahasa, faktor psikologis dan biologis, serta pengalaman inderawi. Hal ini menunjukkan keholistikan model konstruksi kreatif dibanding model lainnya.

Penelitian ini menghasilkan model perangkat pembelajaran keterampilan berbicara bahasa Indonesia berdasarkan pendekatan komunikatif-kontekstual yang dapat digunakan untuk mahasiswa asing di IAIN Tulungagung. Sehubungan dengan itu, hasil penelitian ini memiliki kontribusi nyata terhadap beberapa pihak yang terkait dengan pembelajaran BIPA di IAIN Tulungagung, yakni dosen BIPA, mahasiswa BIPA, penyusun buku BIPA, dan kurikulum BIPA.

\section{METODE}

Penelitian ini termasuk dalam penelitian pengembangan. Desain pengembangan yang digunakan dalam penelitian ini adalah model R2D2 (Recursive Reflective Design and Development) dari Willis (1995). Model ini terdiri atas tiga kegiatan, yakni (1) penetapan (define), (2) desain (design) (3) pengambangan (develop), serta (4) penyebarluasan (disseminate).

Produk yang telah dikembangkan, diujicobakan kepada 20 mahasiswa BIPA dari Thailand, 2 instruktur BIPA, dan 1 ahli pembelajaran BIPA. Uji coba dalam R2D2 ditujukan untuk memperoleh umpan balik yang dapat digunakan untuk memperbaiki produk yang telah dikembangkan. Umpan balik tersebut berupa kritik, komentar, dan saran. Produk yang telah disempurnakan kemudian dideseminasikan kepada pengguna yang lebih besar jumlahnya.

Ada dua jenis data yang dikumpulkan dalam penelitian ini, yakni data kualitatif dan data kuantitatif. Data kualitatif dalam penelitian ini berupa data lisan dan tertulis yang digunakan sebagai dasar untuk merevisi produk. Data tersebut berupa catatan, komentar, kritik, saran, koreksi, atau usul yang dituliskan pada produk 
yang diujicobakan, khususnya pada lembar catatan yang disediakan. Sementara data kuantitatif berupa skor hasil pembelajaran keterampilan berbicara bahasa Indonesia yang digunakan sebagai acuan untuk menilai efektivitas produk.

Data dalam penelitian ini dikumpulkan dengan teknik wawancara, angket, dan dokumentasi. Teknik wawancara digunakan untuk mendapatkan data berupa komentar langsung dari dosen dan mahasiswa pengguna produk pengembangan ini. Teknik angket digunakan untuk mendapatkan masukan berupa kritik, saran, dan pendapat yang berkaitan dengan produk penelitian ini. Sementara teknik dokumentasi digunakan untuk mengumpulkan data berupa skor evaluasi yang diperoleh oleh mahasiswa.

Instrumen yang digunakan untuk mengumpulkan data adalah panduan wawancara, kisi-kisi angket, dan alat tes. Panduan wawancara digunakan untuk mengarahkan pertanyaan pada informasi yang dibutuhkan. Kisi-kisi angket digunakan untuk mendapatkan informasi penting dari mahasiswa yang belajar dengan buku hasil penelitian ini. Sementara alat tes digunakan untuk mendapatkan skor mahasiswa sebagai indikator keberhasilan dan kegagalan pembelajaran dengan buku hasil penelitian ini.

Subjek uji coba penelitian ini ada tiga kelompok, yakni ahli pembelajaran BIPA, dosen BIPA, dan mahasiswa BIPA. Ahli pembelajaran BIPA dipilih dari Sanggar Kampung Indonesia Tulungagung yang setiap tahunnya mengelola kelas BIPA. Dosen BIPA dipilih dari pengajar bahasa Indonesia IAIN Tulungagung. Sementara mahasiswa BIPA adalah 20 mahasiswa Pattani yang kuliah di IAIN Tulungagung.

Data yang terkumpul segera dianalisis. Mengingat data yang dikumpulkan berupa data kualitatif dan kuantitatif, analisis data dilakukan secara kualitatif dan kuantitatif. Analisis data kualitatif digunakan untuk menganalisis data hasil angket dan uji ahli. Sementara data kuantitatif yang berupa skor hasil evaluasi pembelajaran BIPA dianalisis dengan teknik statistik deskriptif dan uji-t. Penggunaan teknik uji-t ini didasarkan pada pertimbangan bahwa terdapat sampel berpasangan karena perlakuan ganda terhadap subjek yang sama. Selisih nilai (deviasi) antara kemampuan awal (pre-test) dan kemampuan akhir (post-test)dianggap sebagai dampak implementasi model perangkat pembelajaran keterampilan berbicara bahasa Indonesia.

\section{HASIL DAN PEMBAHASAN}

Pendekatan komunikatif-kontekstual dalam pengajaran keterampilan berbicara mensyaratkan adanya bahan ajar yang bersumber dari penggunaan bahasa secara nyata dalam kehidupan sehari-hari. Dengan demikian, bahasa yang dipelajari mahasiswa di kelas tidak memiliki kesenjangan dengan penggunaan bahasa dalam pergaulan sehari-hari. Untuk itu, tema, topik, dan ungkapan yang diajarkan harus bersumber dari penggunaan bahasa secara nyata di masyarakat.

Dalam rangka memenuhi kebutuhan itu, peneliti mengembangkan perangkat pembelajaran BIPA dengan pendekatan komunikatif-kontekstual. Sejalan dengan tujuannya, penelitian ini menghasilkan (1) Rencana Program Pengajaran (RPP) Keterampilan Berbicara Bahasa Indonesia bagi Penutur Asing dan (2) perangkat pembelajaran keterampilan berbicara Bahasa Indonesia bagi penutur asing.

\section{Rencana Program Pengajaran (RPP) Keterampilan Berbicara Bahasa Indo- nesia bagi Penutur Asing (BIPA) dengan Pendekatan Komunikatif-Kontekstual \\ Sebelum menyusun buku ajar, peneliti perlu menyusun Rencana Program Pem- belajaran (RPP). RPP yang sudah disusun kemudian dikonsultasikan kepada pakar BIPA untuk mendapat kritik dan masukan.}


Dalam penelitian ini, ada dua pakar BIPA yang dijadikan sebagai tim ahli, yaitu Dr. Mujianto, M.Pd dan Marista Dewi Ramayantis, M.Pd. Mereka berdua adalah ahli pembelajaran BIPA di sanggar Kampung Indonesia Tulungagung, sanggar yang didirikan untuk melayani mahasiswa asing yang ingin belajar bahasa dan budaya Indonesia di Tulungagung. Sejauh ini, sanggar ini telah memberikan pembelajaran bahasa dan budaya Indonesia kepada mahasiswa universitas Walailak Thailand yang mengikuti program in country.

Kritik dan masukan dari para ahli kemudian dijadikan pertimbangan untuk memperbaiki RPP yang ada. RPP yang disusun, menurut penilaian para pakar BIPA dari sanggar Kampung Indonesia Tulungagung sudah memenuhi unsurunsur kekomunikatifan dan kekontekstualan. Selain itu, kompetensi dasar yang dirancang juga sesuai dengan konteks komunikasi nyata dalam kehidupan sehari-hari. Berdasarkan RPP yang sudah diperbaiki, buku ajar keterampilan berbicara bahasa Indonesia bagi penutur asing disusun.

Mengingat bahasa Indonesia lahir dari masyarakat Indonesia yang multikultural, maka aspek-aspek multikultural bahasa juga harus menjadi bahan pertimbangan dalam menyusun bahan ajar BIPA, terlebih jika yang belajar bahasa Indonesia adalah mahasiswa asing. Hal ini sejalan dengan beberapa hasil penelitian pengembangan bahan ajar BIPA seperti yang dilakukan oleh Sugiono (1995), Hertiningsih (2007), Gunawan (2007), dan Suyitno (2010).

Dalam mempersiapkan bahan ajar BIPA, Sugiono (1995) menganjurkan untuk mempertimbangkan aspek komunikatif dan tematis. Bahasa yang diajarkan haruslah bersumber dari kehidupan nyata penggunaan bahasa. Konteks komunikasi nyata dalam kehidupan sehari-hari merupakan materi bahasa otentik yang bermuatan budaya Indonesia yang plural (Hertiningsih, 2007). Yang juga penting diperhatikan adalah tujuan mahasiswa mempelajari bahasa Indonesia (Suyitno, 2007; Gunawan, 2007).

\section{Buku Ajar Keterampilan Berbicara BIPA dengan Pendekatan Komunikatif- Kontekstual}

Berdasar RPP yang sudah diperbaiki, peneliti mengembangkan buku ajar keterampilan berbicara bahasa Indonesia bagi penutur asing. Buku ajar tersebut disusun dengan model Recursive, Reflective, Design and Development (R2D2) yang diadopsi dari Willis (1995). Model ini memiliki empat prinsip, yaitu (1) recursion, (2) reflection, (3) nonlinier, dan (4) design participatory.

Prinsip recursion memungkinkan peneliti untuk membuat keputusan sementara dan meninjaunya kembali serta membuat perbaikan jika diperlukan. Pada tahap ini, peneliti membuat RPP sementara dan buku ajar sementara untuk dikonsultasikan kepada pakar pembelajaran BIPA di Sanggar Kampung Indonesia Tulungagung, yakni Dr. Mujianto, M.Pd dan Marista Dwi Rahmayantis, M.Pd. Kritik dan masukan dari mereka digunakan unruk memperbaiki draf RPP dan buku ajar tersebut.

Prinsip reflection memungkinkan peneliti untuk memikirkan ulang, menemukan umpan balik dan ide-ide dari banyak sumber selama proses pengembangan. Pada tahap ini, peneliti membaca ulang RPP dan buku ajar sementara. Sambil membaca berbagai sumber dan memperhatikan kritik dan masukan dari pakar, RPP dan buku ajar diperbaiki.

Prinsip nonlinier memungkinkan peneliti untuk mengembangkan buku ajar secara tidak urut dengan format yang baku mulai awal hingga akhir. Peneliti bisa memulai dengan tujuan sementara dan dikembangkan selama proses penyusunan hingga buku ajar selesai. Dalam hal ini, peneliti memulai dari langkah-langkah yang mungkin dikerjakan terlebih dahulu, tidak harus urut sesuai prosedur 
pengembangan yang ditentukan pada metode pengembangan.

Terakhir, prinsip design participatory membolehkan peneliti untuk melibatkan orang lain dalam tim untuk merencanakan dan mengembangkan. Dalam hal ini peneliti melibatkan dua ahli BIPA dan seorang anggota peneliti. Kritik dan masukan dari mereka menjadi pertimbangan untuk memperbaiki buku ajar yang ada.

Pendekatan komunikatif-kontekstualmengharuskan pembelajaran keterampilan berbicara bahasa Indonesia harus berdasarkan kondisi nyata penggunaan bahasa Indonesia dalam kehidupan sehari-hari. Mengenai buku ajar dengan pendekatan komunikatif, Nunan (1991) menyarankan lima prinsip yang perlu diperhatikan, yakni (1) interaksi komunikatif, (2) teks otentik, (3) belajar bahasa dan manajemen belajar, (4) pengalaman personal, dan (5) hubungan bahasa di kelas dan luar kelas. Karena itu, buku ajar yang dikembangkan harus memenuhi unsur-unsur di atas.

Buku ajar yang dikembangkan ini menurut para pakar sudah sesuai dengan sayarat-syarat yang disarankan oleh Nunan. Buku ajar ini terdiri atas 17 unit yang berisi contoh ungkapan-ungkapan penting bahasa Indonesia yang biasa digunakan dalam komunikasi sehari-hari dalam situasi atau konteks tertentu. Selain itu, buku ini juga memberikan beberapa contoh dialog dalam berbagai konteks agar pebelajar mampu menggunakan bahasa Indonesia dalam konteksnya. Ini sejalan dengan saran Ghazali (2010), yakni tujuan pembelajaran berbicara adalah untuk menguasai dua kompetensi, yakni (1) mampu memahami tuturan mitra tutur, dan (2) mampu memproduksi tuturan yang mudah dipahami oleh mitra tutur.

Buku yang sudah direvisi kemudian diujicobakan. Buku ajar ini diujicobakan kepada (1) instruktur BIPA IAIN Tulungagung, yakni 2 dosen, (2) uji ahli, yakni 2 intruktur BIPA di Sanggar Kampung
Indonesia Tulungagung, dan (3) 20 mahasiswa asing di IAIN Tulungagung. Uji coba dalam model R2D2 bertujuan untuk mendapatkan umpan balik yang dapat dimanfaatkan untuk memperbaiki buku ajar yang diujicobakan.

Hasil perbaikan buku ajar kemudian diujicobakan untuk mengetahui efektivitas buku ajar tersebut. Uji efektivitas dilakukan untuk mengetahui efektivitas pembelajaran yang memanfaatkan buku ajar yang dikembangkan dalam penelitian ini terhadap peningkatan kemampuan berbicara bahasa Indonesia mahasiswa BIPA. Uji efektivitas dilakukan dengan rancangan pra-eksperimen, yakni dengan melakukan pretes dan postes pada kelompok tunggal tanpa kelompok kontrol. Hasil analisis uji $\mathrm{t}$ menunjukkan perbedaan yang signifikan antara skor pretes dan postes. Perbedaan ini terjadi karena adanya perlakuaan, yakni dilaksanakannya pembelajaran keterampilan berbicara dengan menggunakan buku ajar keterampilan berbicara dengan pendekatan komunikatif-kontekstual.

Dengan adanya perlakuan, skor kemampuan berbicara mahasiswa BIPA IAIN Tulungagung menjadi lebih baik dibandingkan dengan skor sebelum adanya perlakuan, yakni $\mathrm{P}<a ́ 0,05$. Dengan demikian dapat disimpulkan bahwa pembelajaran keterampilan berbicara bahasa Indonesia dengan menggunakan Buku Ajar Keterampilan Berbicara Bahasa Indonesia bagi Penutur Asing berpengaruh secara signifikan terhadap hasil pembelajaran berbicara pada mahasiswa BIPA.

Selain itu, hasil analisis data dari angket menunjukkan bahwa RPP keterampilan berbicara bahasa Indonesia untuk penutur asing ini sudah memenuhi unsur-unsur yang disarankan oleh Nunan (1991). Hal ini didukung hasil angket yang diberikan kepada ahli BIPA. Demikian juga para mahasiswa asing yang belajar BIPA menggunakan buku ajar ini menyatakan bahwa mereka senang dan merasa 
mudah belajar bahasa Indonesia dengan menggunakan buku ajar ini. Hasil angket menunjukkan bahwa $87 \%$ mahasiswa BIPA merasa antusias dan senang karena contoh ungkapan dan dialog yang disajikan dalam buku ajar ini membantu mereka mampau berbicara bahasa Indonesia dalam waktu yang singkat. Dengan waktu belajar 4 jam sehari (2 jam pagi, 2 jam sore; 6 hari dalam seminggu), mereka mampu berbicara bahasa Indonesia dalam waktu lima minggu.

\section{SIMPULAN}

Model perangkat pembelajaraan yang dikembangkan meliputi RPP dan buku ajar keterampilan berbicara bahasa Indonesia bagi penutur asing. Buku ajar tersebut disusun dengan model Recursive, Reflective, Design and Development (R2D2) yang memiliki empat prinsip, yaitu (1) recursion, (2) reflection, (3) nonlinier, dan (4) design participatory.

Buku ajar yang dikembangkan ini menurut para pakar sudah memenuhi unsur-unsur yang harus ada. Buku ajar ini terdiri atas 17 unit yang berisi contoh ungkapan-ungkapan penting bahasa Indonesia yang biasa digunakan dalam komunikasi sehari-hari dalam situasi atau konteks tertentu. Selain itu, buku ini juga memberikan beberapa contoh dialog dalam berbagai konteks agar pebelajar mampu menggunakan bahasa Indonesia dalam konteksnya.

Uji efektivitas dilakukan dengan rancangan pra-eksperimen, yakni dengan melakukan pretes dan postes pada kelompok tunggal tanpa kelompok kontrol. Hasil analisis uji $t$ menunjukkan perbedaan yang signifikan antara skor pretes dan postes, yakni $\mathrm{P}<\alpha 0,05$. Dengan demikian dapat disimpulkan bahwa pembelajaran keterampilan berbicara bahasa Indonesia dengan menggunakan Buku Ajar Keterampilan Berbicara Bahasa Indonesia bagi Penutur Asing dengan pendekatan komunikatif-kontekstual berpengaruh secara signifikan terhadap hasil pembelajaran berbicara pada mahasiswa BIPA.

Selain itu, hasil analisis data dari angket menunjukkan bahwa mahasiswa asing yang belajar BIPA menggunakan buku ajar ini merasa senang dan merasa mudah belajar bahasa Indonesia dengan menggunakan buku ajar ini. Hasil angket menunjukkan bahwa $87 \%$ mahasiswa BIPA merasa antusias dan senang karena contoh ungkapan dan dialog yang disajikan dalam buku ajar ini membantu mereka mampau berbicara bahasa Indonesia dalam waktu yang singkat. Dengan waktu belajar 4 jam sehari (2 jam pagi, 2 jam sore; 6 hari dalam seminggu), mereka mampu berbicara bahasa Indonesia dalam waktu lima minggu.

\section{UCAPAN TERIMA KASIH}

Penelitian ini dapat terselesaikan karena sumbangsih dari berbagai pihak. Untuk itu, ucapan terima kasih yang tulus disampaikan kepada mereka yang telah berjasa membantu terselesaikannya penelitian ini. Ucapan terima kasih yang tulus terutama disampaikan kepada Rektor IAIN Tulungagung yang telah memberikan tugas kepada peneliti untuk melaksanakan pengembangan buku ajar ini. Ucapan terima kasih juga disampaikan kepada Dr. Mujianto, M.Pd dan Marista Dwi Rahmayantis, M.Pd sebagai reviewer yang banyak memberi masukan dan koreksi untuk perbaikan hasil penelitian ini. Selain itu, terima kasih yang tulus juga disampaikan kepada 20 mahasiswa asing dari Pattani Thailand yang berkenan memberi komentar, kritik, dan menjadi subjek uji coba buku ajar yang dikembangkan.

\section{DAFTAR PUSTAKA}

Collins, James T. 2014. "Keragaman Bahasa dan Kesepakatan Masyarakat: Pluralitas dan Komunikasi". Makalah Seminar Internasional Pendidikan Berbasis Keragaman Budaya: Sumbangan Bahasa dan Sastra Indonesia. Jakarta: 
UIN Syarif Hidayatullah Jakarta 4-6 November 2014.

Ghazali, Abdul Syukur. 2010. Pembelajaran

Keterampilan Berbahasa dengan Pendekatan Komunikatif-Interaktif. Bandung: Refika Aditama.

Gunawan, Samuel. 2007. “Merancang BIPA sesuai dengan Tuntutan Pelanggan yang sangat Beragam dalam Program Pertukaran Mahasiswa". http:// www.pusatbahasa.diknas.go.id/laman/nawala.

Hertiningsih, Anneke. 2007. "Pengembangan Bahan Ajar BIPA melalui Materi Otentik yang Bermuatan Budaya Indonesia". Dalam http://www. pusatbahasa.go.id/laman/nawala.

Huda, Nuril. 1985. 'Teori Monitor dan Pengajaran Bahasa Asing". Dalam Linguistik Indonesia, MLI No. 5. Agustus 1985.

Krashen, Stephen, D. 1981. Second Language Acquisition and Second Language Learning. Oxford: Pergamon Press.

Nunan, David. 1991. Language Teaching Methodology: a Text Book for Teachers. New York: Printice Hall

Sammeng, Andi Mappi. 1995. "Pengajaran Bahasa Indonesia sebagai Bahasa Asing serta Peranannya". Makalah disampaikan dalam Konggres BIPA 1995 Fakultas Sastra Universitas Indonesia.
Saryono, Djoko. 1992. “Beberapa Teori Pemerolehan Bahasa". Hasil Penelitian. Tidak Dipublikasikan. Malang: IKIP Malang.

Subangun. 2014."Peran Bahasa Indonesia dalam Membangun Peradaban Bangsa-bangsa di Kawasan Asean". MakalahSeminar Internasional Bahasa Melayu sebagai Pemecah Masalah Global. Universiti Rajabhat Yala, Thailand.

Sugiono, S. 1995. “Pendekatan KomunikatifIntegratif-Tematis dalam Pengembangan Bahan dan Metodologi Pengajaran BIPA di Indonesia". Makalah disampaikan dalam Kongres BIPA 1995 di Fakultas Sastra Universitas Indonesia.

Susanto, Gatut dan Rofiuddin, 2014. Peta Pembelajaran BIPA dan Peluang Bahasa Indonesia sebagai Bahasa Resmi ASEAN. Makalah seminar Internasional Bahasa Melayu sebagai Pemecah Masalah Global. Universiti Rajabhat Yala, Thailand.

Suyitno, Imam. 2010. “Pengembangan Materi Pembelajaran BIPA Berdasarkan Tujuan Belajar Pelajar Asing". Pidato Pengukuhan Guru Besar. Malang: Universitas Negeri Malang.

Willis, J. 1995. “A Recursive, Reflective Instructional Design Model Based on Construction-Interpretative Theory". In Eduational Technology. 35(6),5-23. 